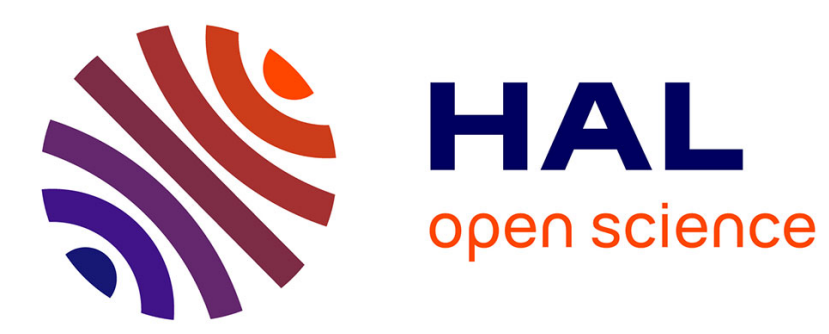

\title{
Mixing the Carrots with the Sticks: Third Party Punishment and Reward
}

\author{
Nikos Nikiforakis, Helen Mitchell
}

\section{To cite this version:}

Nikos Nikiforakis, Helen Mitchell. Mixing the Carrots with the Sticks: Third Party Punishment and Reward. 2014. halshs-00924995

\section{HAL Id: halshs-00924995 https://shs.hal.science/halshs-00924995}

Preprint submitted on 7 Jan 2014

HAL is a multi-disciplinary open access archive for the deposit and dissemination of scientific research documents, whether they are published or not. The documents may come from teaching and research institutions in France or abroad, or from public or private research centers.
L'archive ouverte pluridisciplinaire HAL, est destinée au dépôt et à la diffusion de documents scientifiques de niveau recherche, publiés ou non, émanant des établissements d'enseignement et de recherche français ou étrangers, des laboratoires publics ou privés. 
Mixing the Carrots with the Sticks:

Third Party Punishment and Reward

Nikos Nikiforakis, Helen Mitchell

December 2013 


\section{GATE Groupe d'Analyse et de Théorie Économique Lyon-St Étienne}

93, chemin des Mouilles 69130 Ecully - France

Tel. +33(0)4 72866060

Fax $+33(0) 472866090$

6, rue Basse des Rives 42023 Saint-Etienne cedex 02 - France

Tel. +33 (0)4 77421960

Fax. +33 (0)4 77421950

Messagerie électronique / Email : gate@gate.cnrs.fr

Téléchargement / Download : http://www.gate.cnrs.fr - Publications / Working Papers 


\title{
Mixing the Carrots with the Sticks: Third Party Punishment and Reward*
}

\author{
Nikos Nikiforakis ${ }^{\dagger}$ \\ CNRS, GATE, Lyon \\ Max-Planck Institute for Research on Collective Goods, Bonn \\ Department of Economics, The University of Melbourne \\ Helen Mitchell \\ Department of Foreign Affairs and Trade, Australian Government
}

January 2013

\begin{abstract}
While the opportunity to punish selfish and reward generous behavior coexist in many instances in daily life, in most laboratory studies, the demand for punishment and reward are studied separately from one another. This paper presents the results from an experiment measuring the demand for reward and punishment by 'unaffected' third parties, separately and jointly. We find that the demand for costly punishment is substantially lower when individuals are also given the ability to reward. Similarly, the demand for costly reward is lower when individuals can also punish. The evidence indicates the reason for this is that costly punishment and reward are not only used to alter the material payoff of others as assumed by recent economic models, but also as a signal of disapproval and approval of others' actions, respectively. When the opportunity exists, subjects often choose to withhold reward as a form of costless punishment, and to withhold punishment as a form of costless reward. We conclude that restricting the available options to punishing (rewarding) only, may lead to an increase in the demand for costly punishment (reward).
\end{abstract}

Keywords: punishment, reward, social norms, norm enforcement, third party JEL Codes: C91, D03, D63, H41

\footnotetext{
* We would like to thank the Co-Editor (Jacob Goeree), two anonymous referees, Aurelie Dariel, Peter Duersch, Simon Loertscher, Tom Wilkening, participants at the Asia-Pacific meetings of the Economic Science Association in Melbourne (2010), the $5^{\text {th }}$ Australian-New Zealand Workshop in Experimental Economics, and seminar participants at Monash University, the University of Innsbruck, and the University of Melbourne for helpful comments and discussions. The results from the 'first wave' of the experiments formed the basis for Helen's Honors thesis at the University of Melbourne. The authors acknowledge funding from the Department of Economics, and the Faculty of Business and Economics at the University of Melbourne.

† Corresponding author: n.nikiforakis@ gmail.com.
} 


\section{Introduction}

An important insight from laboratory experiments in the last 30 years is that many individuals are willing to incur a cost to punish selfish and reward generous behavior, even in one-shot interactions. The propensity to punish has been most clearly demonstrated in experiments using the ultimatum game (e.g., Güth et al., 1982), the public good game (e.g., Fehr and Gächter, 2000), and the third party punishment game (e.g., Fehr and Fischbacher, 2004). The propensity to reward generous behavior has been illustrated in experiments based on the trust game (e.g., Berg, Dickhaut and McCabe, 1995) and the gift exchange game (e.g., Fehr, Kirchsteiger and Riedl, 1993). The findings from these games have been central to the development of new theoretical models in which individuals are assumed to have social preferences and thus may be willing to incur a cost to alter the material payoff of other individuals. ${ }^{1}$

Most laboratory studies allow participants to either punish or reward others. However, in many instances in daily life, punishment opportunities coexist alongside reward opportunities. ${ }^{2}$ This raises the question of whether the demand for costly punishment (reward) may be affected by the mere existence of reward (punishment) opportunities and, if so, in what way. The present study addresses this question by using a game similar to that introduced in the literature by Fehr and Fischbacher (2004). In the game, an individual dictates the division of an endowment between herself and a receiver. A third player must decide whether to use part of his endowment to reward or punish the dictator. The demand for costly reward and punishment is examined separately and together. Punishing is costly both for the third party and for the dictator who receives the punishment. Rewarding is costly for the party, but beneficial for the dictator.

If individuals have preferences over bundles of material payoffs only -- as assumed by recent models of social preferences -- the demand for costly punishment (reward) should be unaffected by the existence or absence of reward (punishment) opportunities in our experiment. Punishment, however, may be more than just a means of altering the material payoff of others. Punishment may be used to express disapproval for selfish behavior (e.g., Noussair and Tucker, 2005; Reuben and van Winden, 2008; Xiao and Houser, 2005). Similarly, reward may be used to express approval for generous behavior. If individuals have a preference for expressing their views about the actions of others and they use punishment and reward to that end, restricting the options available to them could lead to overestimating

\footnotetext{
${ }^{1}$ As Camerer and Fehr (2004, p. 55, emphasis added) write: "Social preferences refer to how people rank different allocations of material payoffs to themselves and others." The willingness to punish or reward may be driven by a desire to reduce inequality in payoffs (e.g., Bolton and Ockenfels, 2000; Fehr and Schmidt, 1999) or a desire to hurt (help) people that have been unkind (kind) (e.g., Cox et al., 2007; Levine, 1998; Rabin, 1993).

${ }^{2}$ In online marketplaces such as eBay, for example, traders can leave either positive or negative feedback; positive feedback is a form of reward as it allows sellers to charge higher prices, while negative feedback is a form of punishment for failing to provide the anticipated level of satisfaction as it lowers the prices sellers can charge (Houser and Wooders, 2006). At work, individuals may reward good colleagues by being courteous and helpful to them, and punish bad ones by ignoring them or complaining to the employer.
} 
the demand for costly punishment and reward. For example, when reward opportunities exist, it is possible that some individuals may express their disapproval simply by withholding rewards - a costless form of punishment. Even if an individual decides to punish, the demand for punishment may be lower as costly punishment may signal greater disapproval when the option to withhold reward exists.

The results from the experiment indicate that the demand for costly punishment is indeed substantially higher when rewarding opportunities do not exist. A similar increase is observed in the demand for costly reward when punishing is not possible. Evidence from a questionnaire indicates that many participants use reward and punishment to signal their approval and disapproval of the 'dictator's' transfer. That is, participants do not use punishment and reward solely for the purpose of altering the monetary payoff of others. In addition, we find that changes in the demand for costly punishment or reward do not affect the amount the 'dictator' transfers to the receiver, but have a pronounced effect on individual earnings in the experiment.

This paper is organized as follows. Section 2 reviews the related literature on punishment and rewards. Section 3 describes the experimental design. Section 4 presents the results from the experiment. Section 5 concludes.

\section{Literature review}

The experimental literature on reward and punishment is vast. Most studies have allowed participants to either punish or reward others. In this section, we discuss studies that either allow both for rewarding and punishing, or examine punishment by 'unaffected' third parties. The focus of all studies in the first category tends to be on the efficacy of costly punishment and reward in upholding cooperation rather than the demand for punishment and reward itself (e.g., Chaudhuri, 2011; Gächter and Herrmann, 2009). We concentrate on the findings related to our research question, that is, on the interaction between reward and punishment opportunities.

Ule, Riedl and Cason (2009) examine participants' willingness to punish in a finitelyrepeated, indirect helping game. At the start of each of the 100 periods, subjects are assigned the role of either the donor or the recipient and are then randomly matched in pairs. In each period, donors observe the recipient's recent behavior as a donor in past periods and must decide whether to "help" the recipient (i.e., increase her earnings), do nothing, or punish her (i.e., reduce her earnings). The authors find that subjects prefer to do nothing rather than punish. Rand et al. (2009) study behavior in an indefinitely-repeated prisoner's dilemma in which subjects can cooperate, defect or punish their partner. They find that subjects are more likely to respond to a defection by withholding cooperation in future rounds than by using costly punishment. An important feature of both Rand et al. (2009) and Ule et al. (2009) is that, unlike in our study, individuals have an incentive to build a good reputation by avoiding 
the use of costly punishment. This may explain, at least partly, the reduced demand for punishment in these studies.

Three further studies examine punishment in conjunction with other means for enforcing cooperation in finitely-repeated, public-good games with fixed groups. Rockenbach and Milinski (2006) find that the frequency of costly punishment is significantly reduced if a separate stage is added at the end of the public-good game allowing individuals to withhold rewards from free riders. However, they also find that the intensity of punishment is higher in the presence of reward opportunities. Sefton, Shupp and Walker (2007) find that the demand for costly punishment is significantly lower in the presence of reward opportunities. Similarly, Noussair and Tucker (2005) observe fewer instances of costly punishment when costless punishment (both for the enforcer and the norm violator) is available.

In contrast to these three studies, Andreoni, Harbaugh and Vesterlund (2003) do not find a reduction in the demand for costly punishment in a finitely-repeated, proposer-responder game when reward opportunities are introduced. Interestingly, unlike in the previous studies, subjects in Andreoni et al. (2003) are randomly rematched in every period of the experiment. This suggests that at least part of the reduction in the demand for costly punishment may be due to strategic concerns arising from the fixed composition of groups.

Understanding the relation between reward and punishment can be difficult when the game is played repeatedly, even if individuals are randomly rematched in every period. For example, Andreoni et al. (2003) find that the introduction of punishment opportunities reduces the demand for costly reward. The authors attribute this to the fact that offers were significantly higher in the treatment where both punishment and reward opportunities were available. As a result, they argue, an offer that may appear worthy of reward in one experimental treatment because of the relatively low offers made by others, may not appear to be worthy of a reward in another treatment. Therefore, while repeated-game designs may be desirable for studying the efficacy of different means in promoting efficiency, a one-shot design is better suited for examining the demand for costly punishment and reward, and for addressing our research question. ${ }^{3}$

In summary, these studies suggest that there could be interaction effects between punishment and reward opportunities. However, the experiments were not designed to address whether and how the existence of reward opportunities affects the demand for costly punishment (and vice versa). In particular, the fact that the game is repeated a number of times makes it difficult to understand the reason for the interaction effect. This is the reason we decided to use a one-shot design in our experiment.

\footnotetext{
${ }^{3}$ Walker and Halloran (2004) study the demand for costly punishment and rewards in a one-shot public-good game. They find that both are equally effective in enforcing cooperation. However, their experimental design does not include a treatment with both reward and punishment opportunities. Sutter, Haigner and Kocher (2010) find that subjects prefer using reward than punishment in a finitely-repeated public good game, even though punishment is more effective in encouraging cooperation.
} 
As a testing ground for our study, we use a modified version of the third-party punishment game (Fehr and Fischbacher, 2004). To date, there have been only a handful of studies using this game (e.g., Fehr and Fischbacher, 2004; Fehr, Hoff and Kshetramade, 2008; Henrich et al., 2006; Marlowe et al. 2008). As the name of the game suggests, individuals in these studies are only allowed to punish the 'dictator', that is, they cannot reward her if she is generous. The typical finding in these studies is that the demand for costly punishment increases as the 'dictator's' transfer decreases. The only studies we are aware of in which third parties can both reward and punish are Charness, Cobo-Reyes and Jimenez (2008) and Almenberg et al. (2011). Charness et al. (2008) investigate third-party punishment and reward in a 'trust game' in which, in some treatments, third parties can punish a selfish responder or reward a trusting sender. Therefore, unlike our experiment, punishment and rewards are applied to different individuals. Almenberg et al. (2011), in a recent study, similar to our experiment, allow third parties to punish and reward the dictator. The authors investigate whether the actions of the third party are sensitive to the number of players affected by the behavior of the dictator, and not whether there is an interaction between reward and punishment opportunities. Therefore, unlike in our experiment, they do not examine behavior in treatments where there are either punishment or reward opportunities only.

\section{Experimental design}

The experiment uses a three-player game similar to that introduced by Fehr and Fischbacher (2004). We examine behavior in three treatments which differ only with respect to the actions available to the third party (Player C).

\subsection{Treatment PR}

Treatment PR is our baseline treatment as it allows both for punishing and rewarding. The game in this treatment is as follows. Player A is given an endowment of 100 ECUs (Experimental Currency Units) and must decide how much of it she wishes to transfer to Player B, $t \in\{0,10,20, \ldots, 100\}$. Player B has no endowment or any decision to make. Player C receives an endowment of 65 ECUs. He can use his endowment to either punish or reward Player A for her transfer (hence the name of the treatment). C's endowment is private information. 4

In order to punish, Player $\mathrm{C}$ must purchase punishment points, $p_{t} \in\{0,1, \ldots, 65\}$. Each punishment point costs Player C 1 ECU and reduces Player A's earnings by 2 ECUs. Similarly, in order to reward, Player C must purchase reward points, $r_{t} \in\{0,1, \ldots, 65\}$. Reward

\footnotetext{
${ }^{4}$ In Fehr and Fischbacher (2004) it was common knowledge that Player C was given 50 ECU. This amount reinforces the salience of the equal split between A and B (which the authors refer to as "the distribution norm"). We decided to endow Player $\mathrm{C}$ with an amount larger than 50 ECU, as an endowment of 50 implies that, unless Player A gives more than 50 ECU to Player B, A will earn more than Player C. Rewarding would therefore increase the earnings difference between $\mathrm{A}$ and $\mathrm{C}$, while punishing would reduce it. We kept the endowment of 65 ECU to Player C private so as not to undermine the saliency of the equal split as a potential benchmark for judging which transfers are generous and which are selfish (McDonald et al., 2012).
} 
points cost 1 ECU and increase Player A's earnings by 2 ECUs. Player C can either reward or punish Player A for a given transfer, therefore, if $r_{t}>0$ then $p_{t}=0$ for a given $t$, and vice versa. ${ }^{5}$ The earnings of player A are given by:

$$
\pi^{A}=100-t+2\left(r_{t}-p_{t}\right) .
$$

Player B's earnings are given by:

$$
\pi^{B}=t \text {. }
$$

Player C's earnings are given by:

$$
\pi^{C}=65-\left(p_{t}+r_{t}\right) \text {. }
$$

Equations (1) and (2) are common knowledge amongst participants as are the implications of reward and punishment for Players A and C, and the fact that the game is played only once. Note that it is possible that Player A could have negative earnings, in which case money was deducted from the $\$ 5$ show-up fee subjects received.

Player $\mathrm{C}$ made his decision using the strategy method. This means that Player $\mathrm{C}$ had to state whether he would like to reward or punish Player A for each possible level of transfer and before finding out what A's transfer was. The responses were incentive compatible as Player $\mathrm{C}$ would pay for any points assigned for the transfer level Player A actually chose.

There are three reasons for using the strategy method. First, it allows us to collect more data per individual thus helping us to better understand the motivation behind individual decisions. Second, it guarantees that we will be able to compare the enforcement decisions across treatments, even if transfers by Player A differ. Third, using the strategy method allows us to compare our results with those reported in previous studies using the third-party punishment game. $^{6}$

\subsection{Treatment $P$}

The game in Treatment $\mathrm{P}$ is identical to that played in treatment PR with one difference. Similar to previous experiments, in treatment $\mathrm{P}$, Player C could only punish Player A but not reward her. To keep decision costs as similar as possible to those in treatment PR, using the strategy method, Player $\mathrm{C}$ was asked to enter the number of punishment points he wished to assign into a first box and then was asked to confirm his decision by typing the same number into a second box, for each of the eleven transfer levels. Thus, Player $\mathrm{C}$ made 22 entries, as in treatment PR.

\footnotetext{
5 The experimental instructions were adapted from Fehr and Fischbacher (2004) and use neutral language. Punishment points were referred to as subtraction points and reward points as addition points. The instructions are available at https://sites.google.com/site/nnikiforakis/.

${ }^{6}$ Brandts and Charness (2011) present a survey of the existing evidence on the impact of the strategy method. They report that the treatment effects obtained when using the strategy method are consistent with those obtained when using the direct-response method.
} 


\subsection{Treatment $\mathbf{R}$}

The $\mathrm{R}$ treatment is the same as the PR treatment except that Player $\mathrm{C}$ can only reward Player A. As in treatment P, to keep decision costs similar to those in treatment PR, Player C was asked to enter the number of reward points they wished to assign into a first box and then was asked to confirm this decision. Table 1 summarizes our experimental design.

\subsection{Subject pool and procedures}

The experiment was conducted at the Experimental Economics Laboratory of the University of Melbourne using z-Tree (Fischbacher, 2007). Subjects were recruited through a database of more than 2,500 volunteers using ORSEE (Greiner, 2004). A total of 327 individuals took part in the experiment. All participants were students at the University of Melbourne with different academic backgrounds (excluding students from psychology or those that had completed their first year in economics). Each individual participated in only one treatment. Participants had not previously participated in an experiment involving punishment or reward.

The experiment was conducted in two 'waves'. 222 subjects participated in the first wave of the experiment. We decided to run a second wave with 105 subjects to include additional questions in the post-experiment questionnaire about whether punishment/reward reflected individuals' disapproval/approval. In the second wave, all individuals not assigned the role of Player A used the strategy method to decide how many points they would assign to Player A if they were allocated the role of Player C. It was common knowledge that Player Cs would be randomly selected after all participants made their decisions. This change does not affect incentives in the game. We also aimed to collect the same number of observations for each treatment in each wave. In our analysis, we control for the procedure used to elicit the decisions by Player C. Our results regarding treatment effects are the same across the two waves.

The smallest experimental session had 12 subjects participating, while the six largest sessions had 30 subjects participating. Upon arrival at the laboratory, subjects were seated in partitioned cubicles and were randomly divided into groups - group composition was not revealed to subjects. At the same time, subjects were randomly allocated the role of either Player A, B or C and received player-specific instructions. ${ }^{7}$ The instructions included control questions to ensure that all subjects understood the game. Before the experiment began, the experimenter read a summary of the instructions. After the experiment ended, subjects

\footnotetext{
${ }^{7}$ In the second wave, participants not assigned the role of Player A received a set of instructions that explained the roles of Player B and C. These participants were asked to make the decision of Player C using the strategy method and were then randomly allocated the role of either Player B or Player C at the end of the experiment. We decided to have all participants not assigned the role of Player A make punishment/reward decisions so that we have a larger sample of participants who would answer the punishment/reward questions in the postexperiment questionnaire.
} 
answered a short questionnaire that included sociodemographic questions and asked how they made their decisions in the experiment.

Sessions lasted on average 40 minutes, including instruction time. On average, participants earned 23.20 Australian Dollars including a \$5 show-up fee. The exchange rate between ECU and the Australian Dollar was 1 ECU $=35$ Australian cents. This meant that the stakes were not trivial as Player A's endowment was \$35 and C's endowment was 22.75 Australian Dollars. At the time of the experiment, the minimum hourly wage in Australia was \$14.31. The exchange rate between the Australian and U.S. Dollar was approximately one.

\subsection{Hypotheses}

We first discuss the prediction for our game under the joint assumption that each player is maximizing his/her earnings and that this is common knowledge. Since punishing and rewarding is costly, the trembling-hand-perfect Nash equilibrium is that Player $\mathrm{C}$ will neither punish nor reward Player A, and that the latter will make a zero transfer to $\mathrm{B}$. The prediction is the same across all treatments. While this assumption seems unrealistic and the corresponding Nash equilibrium is known to be a poor predictor of behavior in games such as ours, it is nevertheless widely used in the literature. We thus present it for completeness.

Recently, economic models have emerged providing different explanations for the willingness of people to punish selfish and reward generous behavior. These models assume that individuals have social preferences (e.g., Bolton and Ockenfels, 2000; Cox et al., 2007; Fehr and Schmidt, 1999; Levine, 1998; Rabin, 1993) and thus may be willing to sacrifice part of their income to alter the material payoff of others. While there are numerous differences across these models, all of them predict that (i) punishment (reward) should increase (decrease) as Player A's transfer decreases, and (ii) behavior should be the same across treatments in our experiment. The intuition for the latter is simple. Individuals in these models are assumed to have preferences over different (material) payoff allocations to themselves and others. ${ }^{8}$ Punishment and reward are simply means for altering material payoffs. Whether an individual will reduce the earnings of another participant and the amount of the reduction does not depend on whether the individual also has the option to increase the earnings of the other player.

\footnotetext{
${ }^{8}$ Some models, such as Cox et al. (2007) and Rabin (1993), allow for these preferences to depend on the intentions of the other player. An action is judged to be kind or unkind and, hence, worthy of reward or punishment, according to a reference material payoff. In Rabin (1993, p.1286), for example, player $j$ determines the kindness of player $i$ by comparing his payoff $\left(\pi_{j}\right)$ to the "equitable payoff". The equitable payoff is defined as the average of the highest and lowest possible payoff that $j$ could earn. Notice that Rabin's definition considers reciprocity between two players: $i$ and $j$. A plausible adaptation of this assumption for our game is that Player $\mathrm{C}$ judges A's kindness by comparing the latter's payoff $\left(\pi_{A}\right)$ to the average of the highest and lowest possible payoff that Player B could earn. Reward and punishment do not affect the earnings of Player B, but could affect those of Player A. However, recall that C's endowment is private information. Therefore, it seems unlikely that C's judgment of A's kindness would be affected by the presence of reward/punishment opportunities in our experiment. We provide evidence that this is indeed the case in section 4.4.
} 
As mentioned previously, recent evidence suggests that individuals may use punishment not only to alter the material payoffs of others, but also to signal their disapproval of a selfish action (e.g., Noussair and Tucker, 2005; Reuben and van Winden, 2008; Xiao and Houser, 2005). When reward opportunities exist, individuals can signal their disapproval without incurring a cost by simply withholding reward. In this case, a punishment $p$ may reflect stronger disapproval when reward opportunities are not restricted. Therefore, if individuals use punishment to express disapproval, controlling for the level of transfer, third parties will demand less costly punishment when reward opportunities exist.

Hypothesis 1: The demand for costly punishment will be higher when reward opportunities are restricted.

Similarly, it seems possible that individuals may use reward to signal their approval of generous actions. When punishment opportunities exist, individuals can signal their approval without incurring a cost by withholding punishment. In this case, a reward $r$ may reflect stronger approval when punishment opportunities are not restricted. Therefore, if individuals use reward to express approval, controlling for the level of transfer, third parties will demand less costly reward when punishment opportunities exist.

Hypothesis 2: The demand for costly reward will be higher when punishment opportunities are restricted.

Note that we do not offer a hypothesis for the impact that our treatments will have on the level of transfer by Player A. The reason is that, while the investment in costly punishment/reward is anticipated to be lower in PR relative to $\mathrm{P}$ and $\mathrm{R}$, some studies have shown that even costless punishment may induce cooperative behavior (Ellingsen and Johannesson, 2008; Masclet et al. 2003; Xiao and Houser, 2009). Therefore, the reduction in the demand for costly punishment and reward may not necessarily lead to lower levels of norm adherence.

\section{Results}

\subsection{The demand for costly punishment}

Figure 1 presents the demand for costly punishment as a function of Player A's transfer. As in previous experiments, we find that as transfers to Player B increase, third parties purchase fewer punishment points in both treatments. While transfers above 50 ECUs receive small amounts of punishment, something also observed in previous experiments (e.g., Fehr and Fischbacher, 2004), as can be seen in Table A1 in the appendix, the punishment of transfers greater than 40 ECUs is not significantly different from zero in either of the treatments. 
Figure 1 provides evidence in support of Hypothesis 1 . As can be seen, there is a substantial reduction in the demand for costly punishment in the PR treatment relative to the $\mathrm{P}$ treatment. On average, subjects assigned 3.13 punishment points in treatment $\mathrm{P}$ and 1.80 in $\mathrm{PR}$, a reduction of 42.5 percent. The difference is statistically significant using the average number of points assigned by an individual across transfers as an independent observation (Mann-Whitney, two-tailed, $p$-value $=0.03$ ).

Table 2 presents a regression analysis of costly punishment. The dependent variable is the number of points individual $i$ assigned for a transfer $t, p_{i t}$. Given the patterns observed in Figure 1 punishment is modeled as a linear function of transfers. ${ }^{9}$ The regression also includes a treatment dummy $(P R)$ and a control for whether the observations are taken from the first or second experimental wave. Further, given that each Player $\mathrm{C}$ makes 11 decisions, we include random effects at the individual level.

The coefficients for the constant in (1) and (2) indicate that Player C assigned 7.19 punishment points to Player A in treatment $\mathrm{P}$ and 3.57 points in treatment $\mathrm{PR}$ for a transfer of zero. The Transfer coefficients in (1) and (2) estimate the change in the demand for costly punishment by third parties when Player A transfers 10 more ECUs to Player B in treatments $\mathrm{P}$ and PR, respectively. The Transfer coefficient estimates from (1) and (2) are significant and negative indicating that an increase in the amount transferred by Player A reduces the punishment from third parties. The reduction is smaller in PR than in $\mathrm{P}$ as can be seen by the significant, positive coefficient of $P R^{*}$ Transfer in column (3). We provide an explanation for this finding in section 4.4. The negative, significant coefficient for PR in column (3) provides additional evidence for the significant reduction in the demand for costly punishment. Therefore, we cannot reject Hypothesis $1 .^{10}$

What causes the reduction in the demand for costly punishment? Is it that fewer people assign punishment points when reward opportunities exist? Is it that people assign fewer points? Or is it both? ${ }^{11}$ In treatment $\mathrm{P}, 59$ percent of subjects punished at least one transfer (29 out of 49), while in treatment PR only 37 percent of subjects did the same (18 out of 49).

\footnotetext{
${ }^{9}$ We follow previous studies in reporting results from linear regressions with individual random effects as this simplifies the interpretation of the coefficients. Tobit regressions yield qualitatively the same results both for punishment and reward. The results are also robust if we only use observations in which transfers were less or equal to $50 \mathrm{ECU}$ for punishment, and greater or equal to $30 \mathrm{ECU}$ for reward (see below).

${ }^{10}$ The Wave coefficient is similar in both $\mathrm{P}$ and PR. This suggests that there was more punishment on average in the second wave of experiments than the first. While this may be a result worthy of further investigation, for our purposes, what is most important is that when an interaction variable $P R^{*} W A V E$ is included in the regressions, we find that it is insignificant ( $p$-value $=0.90$ ). Thus, our treatment effects are unaffected by this parameter. We also tried including additional socio-demographic characteristics in regression (3) to check the robustness of our results. When Age, Economics [major] and Gender variables are included in the estimation, our results are unaffected.

${ }^{11}$ One may wonder whether the reduced demand for costly punishment could be due to subjects switching from punishing to rewarding. This is not the case however, as can be easily seen by examining the demand for punishing transfers of zero in Figure 1. Such transfers are almost never rewarded. Also, if this explanation was behind the reduction in the demand for costly punishment, we would expect that the demand for points (either reward or punishment points) should be at least as high in treatment PR as in P. However, controlling for the level of transfer this is almost never the case.
} 
Columns (4) and (5) in Table 2 disaggregate the demand for costly punishment using a hurdle model. The likelihood of punishment is modeled separately from the severity of punishment conditional on punishment occurring (Nikiforakis, 2008). As can be seen in column (4), an increase in the transfer by Player A reduces significantly the probability that he will be punished. The probability of punishment is significantly lower in treatment PR. While the amount of points assigned is smaller in PR (column 5), the reduction is far from being significant. We therefore conclude:

Result 1: Controlling for the transfer by Player A, the demand for costly punishment is 42.5 percent lower when reward opportunities exist. This difference is significant and is driven by the reduced number of individuals punishing when reward opportunities exist.

\subsection{The demand for costly reward}

Figure 2 presents the demand for costly reward as a function of Player A's transfer. The figure illustrates that individuals purchase more reward points as transfers to Player B increase in both treatments. Transfers of less than 20 ECUs receive small rewards, but as can be seen in Table A1 in the appendix, rewards are not significantly different from zero for transfers less than 30 ECUs in R and less than 50 ECUs in PR.

Figure 2 shows that, in line with Hypothesis 2, the demand for costly reward in treatment $\mathrm{PR}$ is lower than in treatment P. On average, subjects assigned 3.81 reward points in PR and 4.95 in $R$, a reduction of 23 percent. The difference is statistically significant using the average number of points assigned by an individual across transfers as an independent observation (Mann-Whitney, two-tailed; $p$-value $=0.03$ ).

Table 3 presents a regression analysis of costly reward similar to that for punishment in the previous section. The dependent variable is the number of reward points individual $i$ assigned for a transfer $t, r_{i t}$. Reward is modeled as a linear function of transfers. We also include a treatment dummy $(P R)$ in column (3) and a control for whether the observations are taken from the first or second experimental wave. Given that each Player C makes 11 decisions, we include random effects at the individual level.

The Transfer coefficients in columns (1) and (2) capture the change in the demand for costly reward as Player A transfers 10 more ECUs to Player B in treatments R and PR, respectively. The Transfer coefficient estimates in columns (1) and (2) are significant and positive indicating that an increase in the transfer by Player A increases the reward received, in both treatments. The insignificant constants in the same regressions indicate that a transfer of zero was not significantly rewarded. The negative, significant coefficient for PR*Transfer in column (3) indicates that the demand for costly reward is lower in treatment PR. We therefore conclude that we cannot reject Hypothesis $2 .{ }^{12}$

\footnotetext{
${ }^{12}$ The Wave variable is insignificant as can be seen in columns (1) and (2) in Table 3. This indicates that the demand for reward was the same in both waves of the experiment. When an interaction variable $P R^{*} W A V E$ is included in the regressions it is insignificant for all treatments ( $p$-value $>0.5)$. We also tested the robustness of
} 
Columns (4) and (5) in Table 3 present the results from the hurdle model for rewards. The negative, significant coefficient of $P R$ in column (4) and the insignificant coefficient of $P R$ in column (5) indicate that the reduction in the demand for costly reward is due to a reduction in the number of individuals who are willing to reward and not due to a reduction in the size of the reward. In treatment R, 70 percent of subjects rewarded at least one transfer (32 out of 46). In contrast, in treatment PR, only 45 percent of the subjects rewarded once or more times (22 out of 49). We therefore conclude:

Result 2: Controlling for the transfer by Player A, the demand for costly reward is 23 percent lower when punishment opportunities exist. This difference is significant and is driven by the reduced number of individuals rewarding when punishment opportunities exist.

\subsection{Costly and costless punishment/reward}

Since Player C's endowment is private information, as mentioned, we have no prior reason to believe that the existence of punishment/reward opportunities should affect the interpretation of the generosity of a given transfer: a transfer of 0 (100) ECU should be considered equally selfish (generous) in all treatments. How do we then explain the fact that individuals who transferred 0 (100) ECU received less punishment (reward) points in treatment PR than in treatment $\mathrm{P}(\mathrm{R})$ ? More precisely, how can we explain the fact that punishment appeared to be less sensitive to changes in transfers in Table 2?

So far, the analysis has considered solely the demand for costly punishment and reward. However, as we saw, third parties appear to withhold reward as a form of costless punishment. Therefore, to evaluate the sensitivity of third parties to changes in transfers, we need to take into consideration both costly and costless punishment. ${ }^{13}$

Figure 3 presents the average change in the earnings of Player A that Player $\mathrm{C}$ caused in each treatment. As can be seen, for transfers less or equal to 50, the slope of the lines in treatments $\mathrm{P}$ and PR is very similar. ${ }^{14}$ Using a linear regression with individual random effects and the same independent variables as in the third column of Table 2, we fail to reject the hypothesis that the slopes are the same for offers less or equal to $50 \mathrm{ECU}$ ( $p$-value=0.116). This implies that, as offers decrease from $50 \mathrm{ECU}$, the change that Player $\mathrm{C}$ caused to the earnings of Player A is the same across treatments P and PR. In other words, the existence of reward opportunities does not affect the extent of punishment when one takes into account the amount of reward withheld.

Figure 3 also shows that, for transfers greater or equal to 50, the slope of the lines in treatments $\mathrm{R}$ and $\mathrm{PR}$ is similar. Using again a linear regression with individual random effects and the same independent variables as in the third column of Table 2, we fail to reject the

our result by controlling for different socio-demographic characteristics. Controlling for Age, Economics [major] and Gender does not affect our results.

${ }^{13}$ We would like to thank an anonymous referee and the co-editor (Jacob Goeree) for suggesting this analysis.

${ }^{14}$ Recall from Table A1 that transfers lower than 50 ECU attracted a significant number of punishment points. Thus, transfers of 50 ECU can be used as a baseline to evaluate Player C's reaction to the choice of Player A. 
hypothesis that the slopes are the same for offers greater or equal to $50 \mathrm{ECU}$ ( $p$ value $=0.992) .{ }^{15}$ This implies that as offers progressively increase from $50 \mathrm{ECU}$, the change that Player C caused to the earnings of Player A is the same across treatments R and PR. This implies that the presence of punishment opportunities does not affect the extent of reward when taking into account the amount of punishment withheld.

Result 3: The marginal incentives of Player A are unaffected by the existence of punishment or reward opportunities.

\subsection{Costly reward and punishment as signals of approval and disapproval}

Why does the introduction of reward opportunities reduce the demand for costly punishment? Why does the existence of punishment opportunities reduce the demand for costly reward? The critical assumption underlying Hypotheses 1 and 2 is that individuals use costly enforcement to signal their approval or disapproval. Our inability to reject hypotheses 1 and 2 provides indirect support for this assumption. In this section, we present evidence providing direct support for this assumption.

In the post-experiment questionnaire in the second wave of experiments, subjects in treatments $\mathrm{P}$ and PR (48 in total) were asked to nominate how many punishment points they would assign to Player A if they strongly disapproved of Player A's transfer to Player B. Similarly, subjects in treatments R and PR (46 in total) were asked how many reward points they would assign if they strongly approved of Player A's transfer. If costly reward and punishment are used to signal approval and disapproval respectively, we would expect to see a positive correlation between subjects' responses and the number of points they assigned in the experiment.

Figure 4 plots the number of punishment points assigned in the experiment by Player $\mathrm{C}$ to Player A, when the latter transferred nothing to B, against the number of points Player $\mathrm{C}$ said she would assign if she strongly disapproved of A's transfer to B. Figure 5 plots the number of reward points assigned by Player $\mathrm{C}$ in the experiment if A transferred $100 \mathrm{ECU}$ to B, against the number of points $\mathrm{C}$ said she would assign to signal strong approval. As can be seen in both figures, there is a clear positive correlation between the plotted variables ( $p$ value $<0.05$, for all cases). This evidence supports the assumption that individuals use punishments to signal disapproval for violating the norm and rewards to signal approval for adhering to the norm. The availability of reward (punishment) opportunities allows individuals to signal their disapproval (approval) by not rewarding (punishing) rather than by demanding costly punishment.

Result 4: The number of points assigned by Player $C$ in the experiment is highly and positively correlated with the number of points participants stated they would assign, if they strongly approved/disapproved of a transfer by Player A.

\footnotetext{
${ }^{15}$ The difference remains insignificant if we consider transfers greater or equal to $30 \mathrm{ECU}$ ( $p$-value $=0.976$ ).
} 


\subsection{Transfers by Player A and earnings}

The average transfer by Player $A$ is 13 ECUs in treatment P, 15.7 ECUs in treatment R, and 17.3 ECUs in treatment PR. Using the transfer of each Player A as an independent observation, we find that none of the pairwise comparisons is statistically significant (MannWhitney, two-tailed, $p$-value>0.22). The fact that the demand for costly reward and punishment differs across treatments together with the fact that transfers norm adherence is unaffected by our treatments, raises the question of how earnings - a measure of efficiency differ across treatments. Individual earnings are highest in treatment $\mathrm{R}$, followed by treatment PR and treatment P. On average, individuals earned 55.5 ECU in R, 53.7 ECU in PR and 46.4 ECU in P. Using the average earnings in a group as an independent observation, we find that earnings in PR are significantly higher than they are in P (Mann-Whitney, two-sided, $p$ value<0.01) and significantly lower than they are in $\mathrm{R}$ (Mann-Whitney, two-sided, $p$ value $=0.03$ ).

Using the actual earnings as a measure of efficiency in our experiment can be misleading as participants assigned the role of Player A could have been matched with a different Player $\mathrm{C}$, which could have led to substantially different earnings. In order to get a better idea of how earnings differ across treatments, we calculated the average change in the earnings of a Player A given his transfer and the average reduction/increase for that level of transfer in the treatment. The average change in earnings given the distribution of transfers was - 15.60 in $\mathrm{P}$, - 4.08 in PR and + 3.30 in R. This implies that while the introduction of reward opportunities increases earnings in our experiment, the introduction of punishment opportunities reduces earnings.

Result 5: Transfers are not significantly different across treatments. However, there is a significant difference in earnings, with earnings being highest in treatment $R$, followed by $P R$ and then $P$.

\section{Concluding remarks}

We studied the demand for costly reward and punishment by 'unaffected' third parties and found a strong interaction effect between the two. In particular, the demand for costly punishment is greatly reduced when reward opportunities exist. Similarly, the demand for costly reward is reduced in the presence of punishment opportunities. These findings suggest that punishment and reward are more than just means for altering the material payoffs of others as assumed by models of social preferences. Participants appear to have a preference for expressing disapproval and approval, and use punishment and reward opportunities to that end. When punishment opportunities are restricted, individuals can only signal their approval by using costly reward. Similarly, when reward opportunities are restricted, individuals can only signal their disapproval by using costly punishment, whereas when reward opportunities exist many individuals signal their disapproval by withholding reward. 
Our study contributes to a recent discussion about the relatively low frequency with which costly punishment is observed outside the laboratory (Balafoutas and Nikiforakis, 2012; Guala, 2011) and the efficiency of costly punishment in promoting cooperation (e.g., Gächter et al., 2008; Engelmann and Nikiforakis, 2012). Previous studies have identified factors that may influence negatively the willingness to use costly punishment such as the risk of counter-punishment (e.g., Balafoutas and Nikiforakis, 2012; Denant-Boermont et al., 2007; Nikiforakis, 2008) and the preference of some individuals to avoid inflicting harm on norm violators (e.g. Masclet et al., 2003; Noussair and Tucker, 2005). Our findings suggest another explanation, namely, that individuals use different means to signal their disapproval such as withholding rewards, and may thus not engage in costly punishment. This is consistent with Dellarocas and Woods (2008) who find that many disappointed buyers on eBay prefer not to leave positive feedback rather than to leave negative feedback. Our evidence also suggests that the absence of reward opportunities in most experiments may exacerbate the inefficiency of costly punishment as a mechanism for enforcing cooperation in daily life.

\section{References}

Almenberg, J., Dreber, A., Apicella C.L., \& Rand D.G. (2011). Third Party Reward and Punishment: Group Size, Efficiency and Public Goods. In Psychology and Punishment. Nova Publishing.

Andreoni, J., Harbaugh, W., \& Vesterlund, L. (2003). The Carrot or the Stick: Rewards, Punishment and Cooperation. The American Economic Review, 93(3), 893-902.

Balafoutas, L., \& Nikiforakis N. (2012). Norm Enforcement in the City: A Natural Field Experiment. European Economic Review, 56 (8), 1773-1785.

Berg, J., Dickhaut, J., \& McCabe, K. (1995). Trust, Reciprocity, and Social History. Games and Economic Behavior, 10, 122-142.

Brandts, J. \& Charness, G. (2011). The Strategy versus the Direct-response Method: A Survey of Experimental Comparisons. Forthcoming Experimental Economics.

Camerer, C. F., \& E. Fehr. 2004. Measuring Social Norms and Preferences using Experimental Games: A Guide for Social Scientists. In Foundations of Human Sociality: Economic Experiments and Ethnographic Evidence from Fifteen Smallscale Societies, ed. J. Henrich, R. Boyd, S. Bowles, C. Camerer, E. Fehr, and H. Gintis, 5595. Oxford: Oxford University Press.

Charness, G., Cobo-Reyes, R., \& Jimenez, N. (2008). An Investment Game with Third-Party Intervention. Journal of Economic Behavior \& Organization , 68, 18-28.

Chaudhuri, A. (2011). Sustaining Cooperation in Laboratory Public Goods Experiments: A Selective Survey of the Literature. Forthcoming Experimental Economics.

Cox, J.C., Friedman, D., \& Gjerstadt, S. (2007). A Tractable Model of Reciprocity and Fairness. Games and Economic Behavior, 59, 17-45. 
Dellarocas, C \& Woods, C.A. (2008). The Sound of Silence in Online Feedback: Estimating Trading Risks in the Presence of Reporting Bias. Management Science 54, 460-476.

Denant-Boemont, L., Masclet, D., \& C. Noussair (2007). Punishment, Counterpunishment and Sanction Enforcement in a Social Dilemma Experiment. Economic Theory, 33(1), 145-167.

Ellingsen, T., \& Johannesson, M. (2008). Anticipated Verbal Feedback Induces Altruistic Behavior. Evolution and Human Behavior, 29, 100-105.

Engelmann, D., \& Nikiforakis, N., 2012. In the Long Run we are all Dead: On the Benefits of Peer Punishment in Rich Environments. University of Mannheim, Department of Economics, Working Paper ECON 12-22.

Fehr, E., \& Fischbacher, U. (2004). Third-party Punishment and Social Norms. Evolution and Human Behavior, 25, 63-87.

Fehr, E., Kirchsteiger, G., \& Riedl, A. (1993). Does Fairness Prevent Market Clearing? An Experimental Investigation. The Quarterly Journal of Economics, 108 (2), 437-459.

Fehr, E., Hoff, K., \& Kshetramade, M. (2008). Spite and Development. American Economic Review: Papers \& Proceedings, 98(2), $494-499$.

Fehr, E. \& Schmidt, K.M. (2006). The Economics of Fairness, Reciprocity and Altruism Experimental Evidence and New Theories. In: Handbook on the Economics of

Giving, Reciprocity and Altruism, Vol. 1, (ed.) Serge-Christophe Kolm and Jean Mercier Ythier, Amsterdam: Elsevier, 615-691.

Fischbacher, U. (2007). Z-Tree: Zurich Toolbox for Readymade Economic Experiments. Experimental Economics, 10, 171-178.

Gächter, S. \& Herrmann, B. (2009). Reciprocity, Culture, and Human Cooperation: Previous Insights and a New Cross-cultural Experiment. Philosophical Transactions of the Royal Society B - Biological Sciences 364, 791-806.

Gächter, S., Renner, E. \& Sefton M. (2008). The Long Run Benefits of Punishment, Science, $322,1510$.

Greiner, B. (2004). An Online Recruitment System for Economic Experiments. MPRA paper.

Guala, F. (2012). Reciprocity Weak or Strong? What Punishment Experiments Do (and Do Not) Demonstrate. Behavioral and Brain Sciences, 35, 1-15.

Güth, W., Schmittberger, R. \& B. Schwarze (1982). An Experimental Analysis of Ultimatum Bargaining. Journal of Economic Behavior and Organization, 3, 367-388.

Henrich, J., McElreath, R., Barr, A., Ensminger, J., Barrett, C., Bolyanatz, A., et al. (2006). Costly Punishment Across Human Societies. Science, 312, 1767.

Houser, D \& Wooders, J. (2006). Reputation in Auctions: Theory and Evidence from eBay. Journal of Economics and Management Strategy, 15 (2), 353-370.

Levine, D. (1998). Modeling Altruism and Spitefulness in Experiments. Review of Economic Dynamics, 1, 593-622. 
Marlowe, F. W., Berbesque, C., Barr, A., Barrett, C. et al. (2008). More 'Altruistic' Punishment in Larger Societies. Proceeding of the Royal Society B - Biological Sciences, 275(1634), 587-592.

Masclet, D., Noussair, C., Tucker, S. \& Villeval, M. C. (2003). Monetary and Nonmonetary Punishment in the Voluntary Contributions Mechanism. American Economics Review, 93(1), 366-380.

McDonald, I., Nikiforakis, N., Olekalns, N., \& Sibly, H. (2012). Social Comparisons and Reference Group Formation: Some Experimental Evidence. Forthcoming Games and Economic Behavior.

Nikiforakis, N. (2008). Punishment and Counter-punishment in Public Good Games: Can we Really Govern Ourselves? Journal of Public Economics, 92(1-2), 91-112.

Noussair, C. \& Tucker, S. (2005). Combining Monetary and Social Sanctions to Promote Cooperation. Economic Inquiry, 43(3), 649-660.

Rabin, M. (1993). Incorporating Fairness into Game Theory and Economics. American Economic Review, 83 (5) 1281-1302.

Rand, D., Dreber, A., Ellingson, T., Fudenberg, D. \& Nowak, M. (2009). Positive Interactions Promote Public Cooperation, Science, 325(5945), 1272-1275.

Reuben, E., \& van Winden, F. (2008). Social ties and coordination on negative reciprocity: The role of affect, Journal of Public Economics, 92(1-2), 34-53.

Rockenbach, B. \& Milinski, M. (2006). The efficient interaction of indirect reciprocity and costly punishment, Nature, 444, 718-723.

Sefton, M., Shupp, R., \& Walker, J. (2007). The Effect of Rewards and Sanctions in Provision of Public Goods. Economic Inquiry, 45 (4), 671-690.

Sutter, M., Haigner, S., \& Kocher, M. (2010). Choosing the stick or the carrot? Endogenous institutional choice in social dilemma situations. Review of Economic Studies 77, 15401566.

Ule, A., Schram, A., Riedl, A. \& Cason, T. (2009). Indirect Punishment and Generosity toward Strangers, Science, 326(5960), 1701-1704.

Walker, J. H., \& Halloran, M. A. (2004). Rewards and Sanctions and the Provision of Public Goods in One-Shot Settings. Experimental Economics. 7(3), 235-47.

Xiao, E. \& Houser, D. (2005). Emotion Expression in Human Punishment Behavior. Proceedings of the National Academy of Sciences of the USA, 102(20), 7398-7401.

Xiao, E. \& Houser, D. (2009). Avoiding the Sharp Tongue: Anticipated Written Messages Promote Fair Economic Exchange. Journal of Economic Psychology, 30, 393-404. 
Figure 1 - The demand for costly punishment

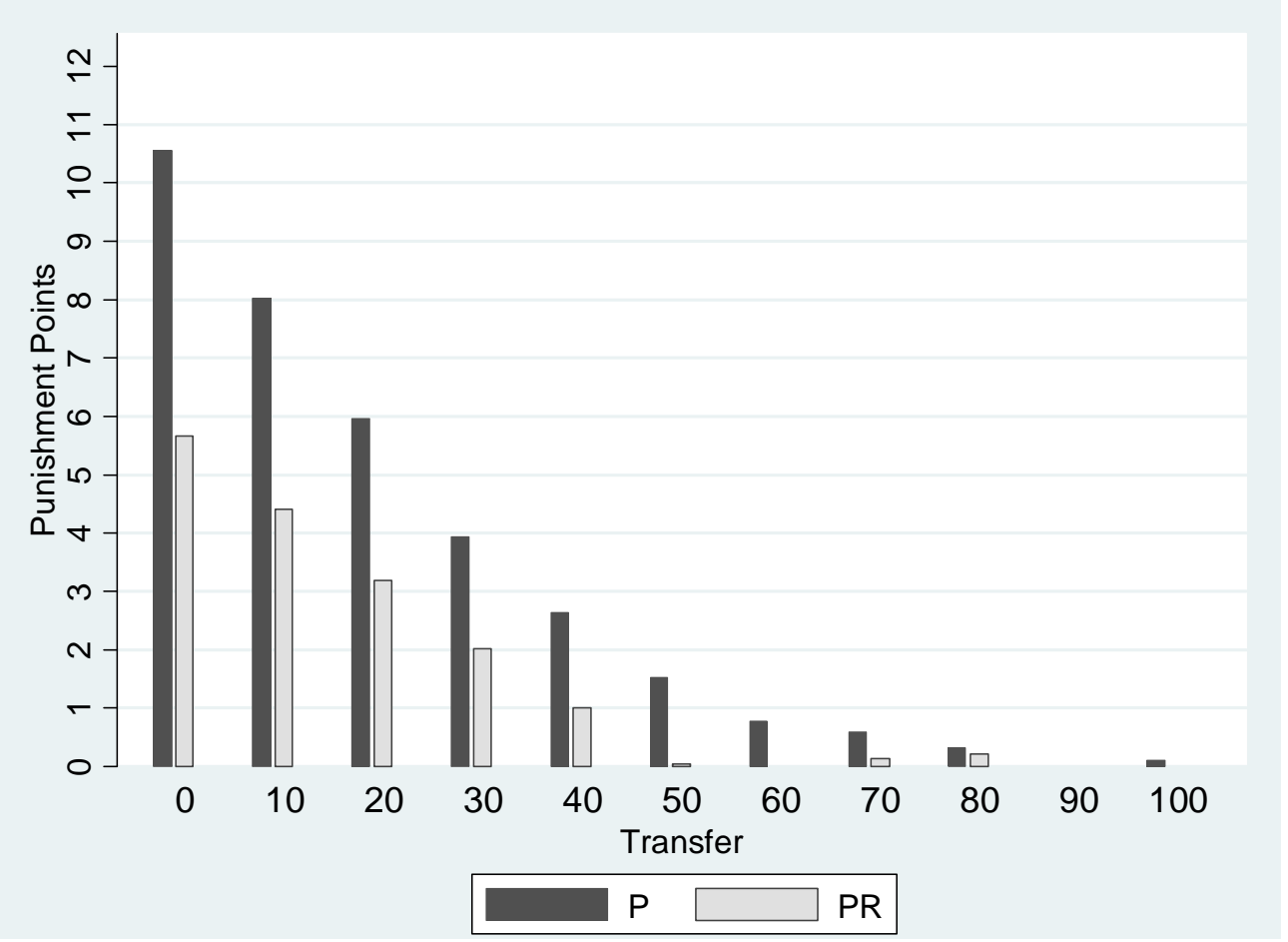

Figure 2 - The demand for costly reward

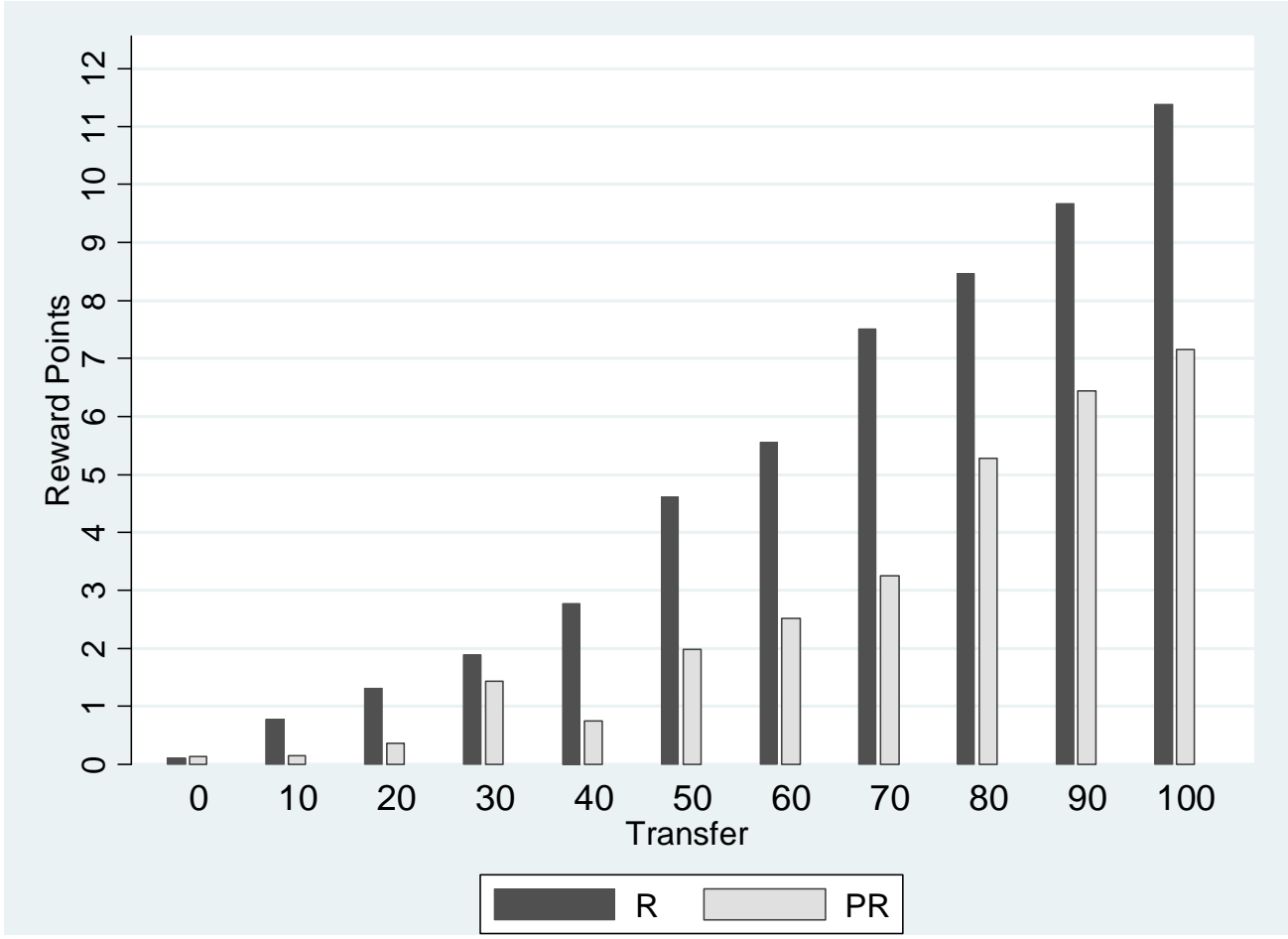

The figures do not include observations from four subjects (ID: 263, 445, 462, and 499). The subjects are included in the statistical analysis, but excluded here to offer a more accurate representation of behavior in the experiment. The responses of these subjects to a post-experiment questionnaire suggest that they were confused. The choices of these subjects can be seen in figures A1 and A2. 
Figure 3 - Average change in Player A's earnings across treatments

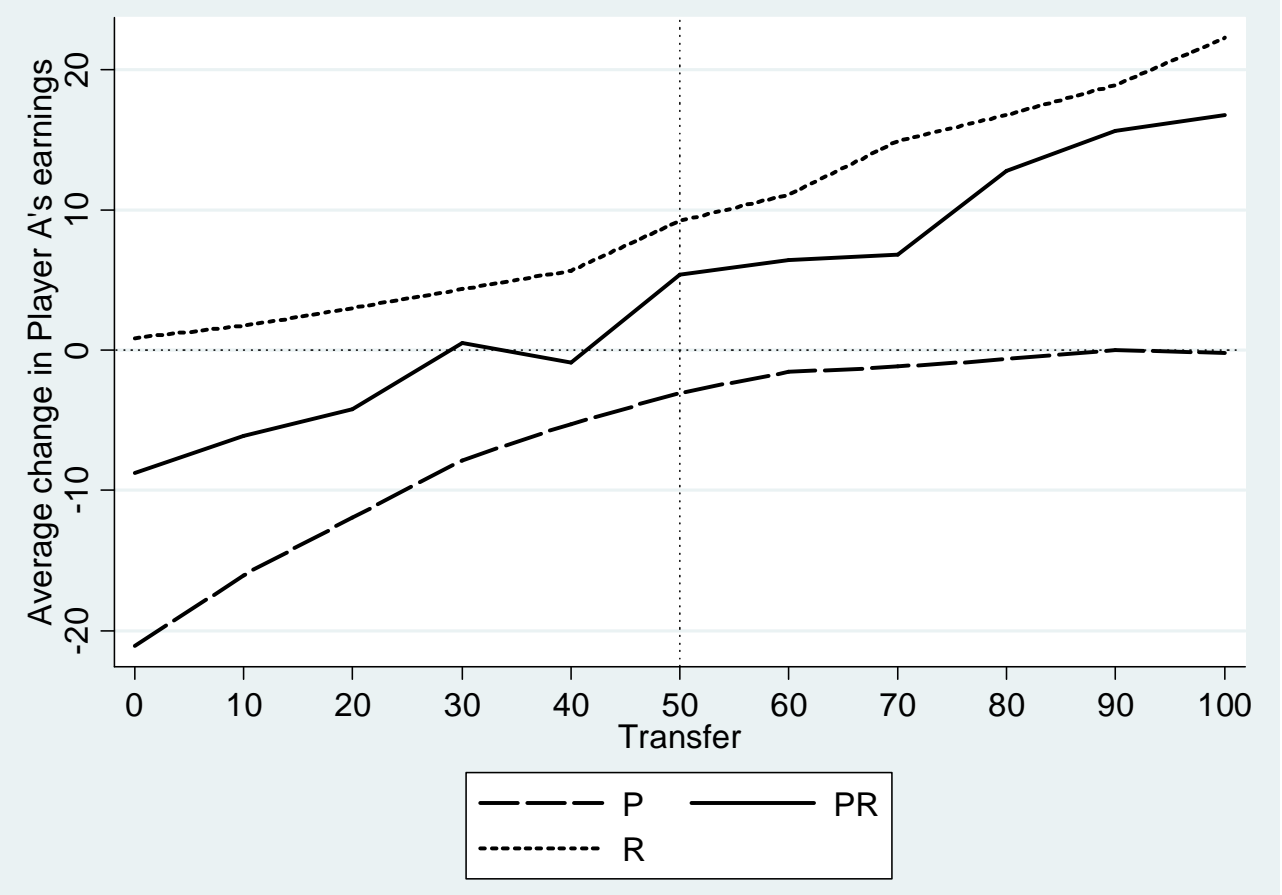


Figure 4 - Does punishment signal disapproval?

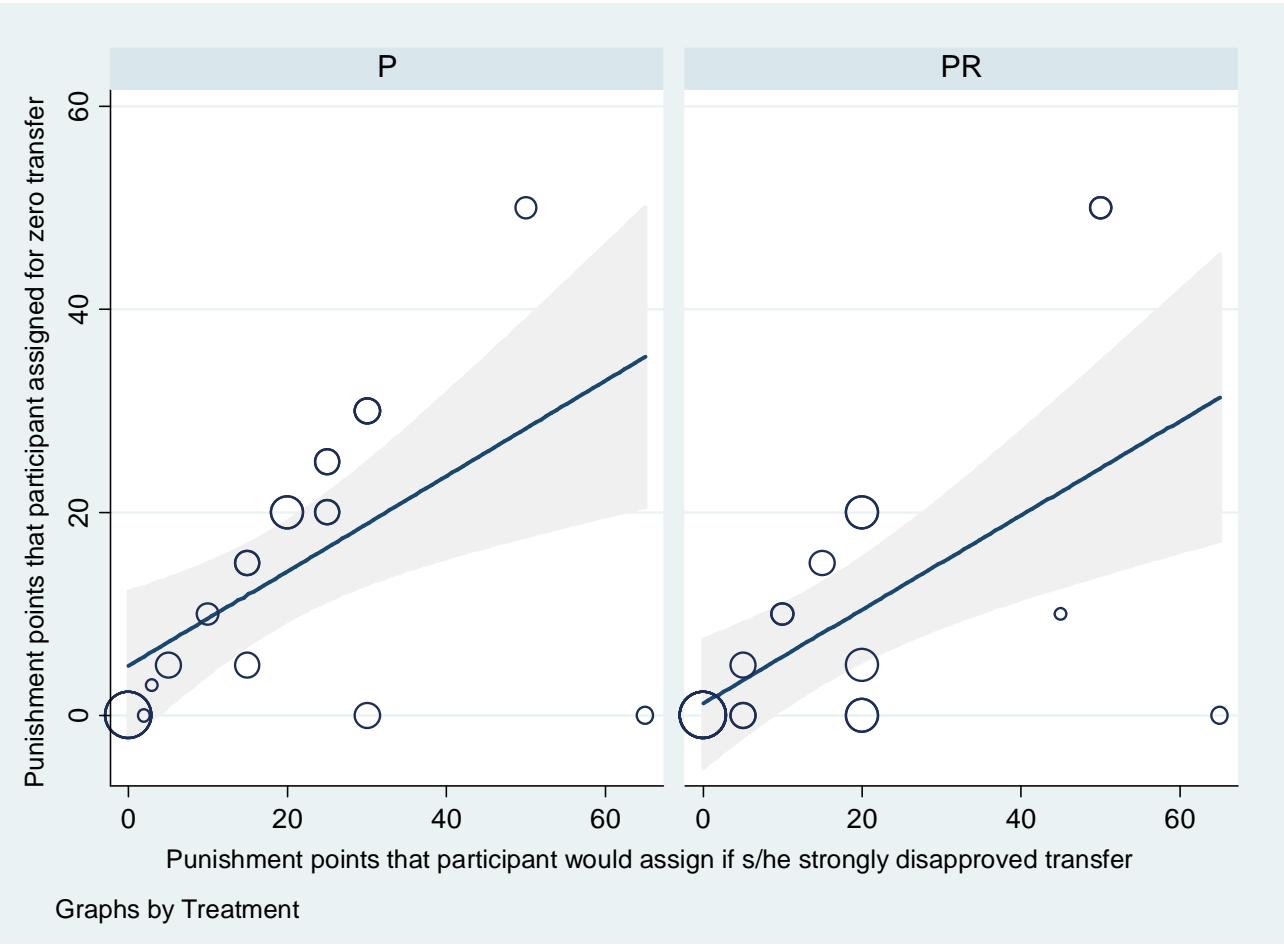

Figure 5 - Does reward signal approval?

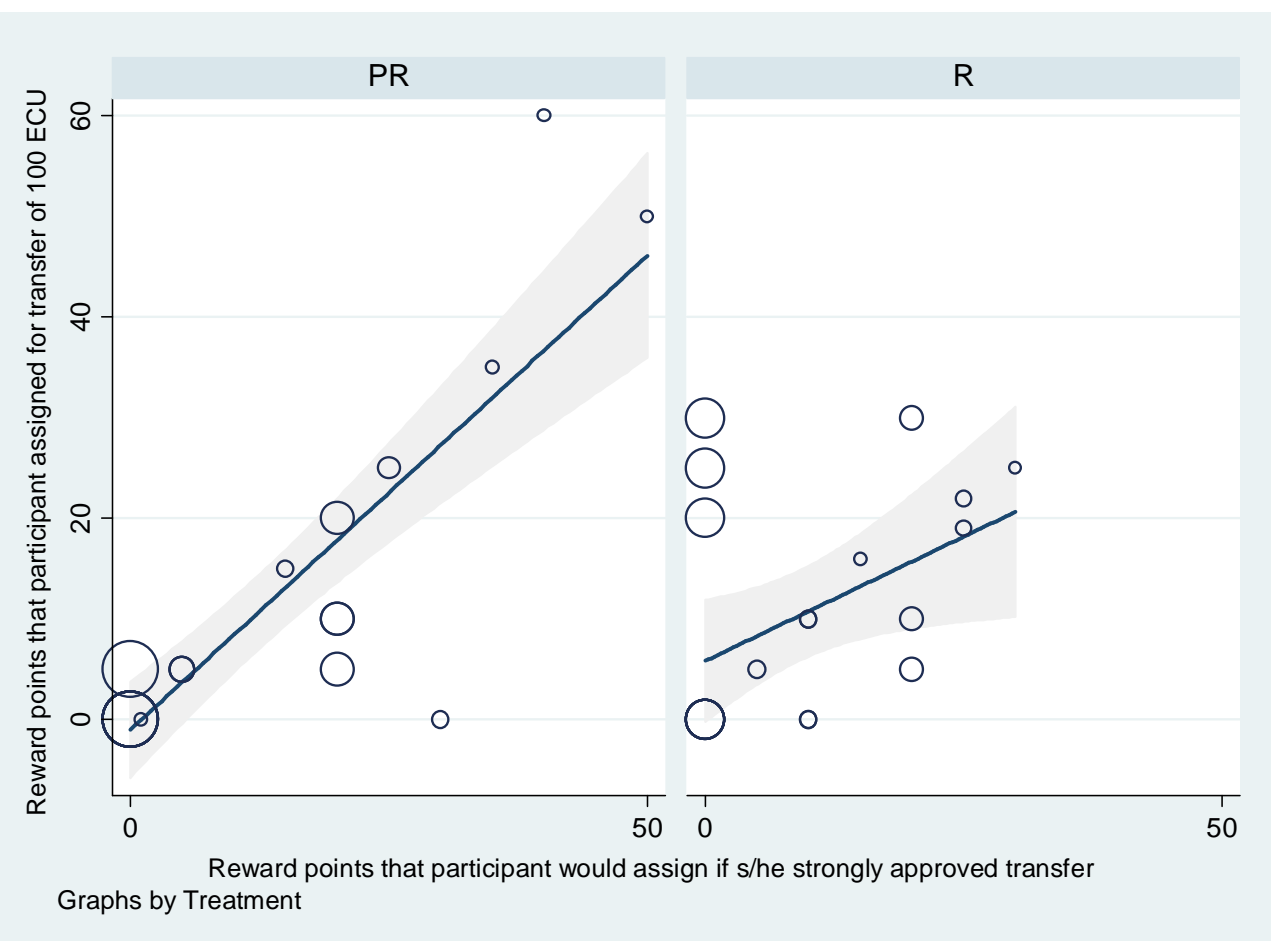


Table 1 - Experimental Design

\begin{tabular}{lccc}
\hline \hline Treatment & Punishment & Reward & \# of participants \\
\hline PR & Yes & Yes & 111 \\
P & Yes & No & 111 \\
R & No & Yes & 105 \\
\hline \hline
\end{tabular}

Table 2 - The Demand for Costly Punishment

\begin{tabular}{|c|c|c|c|c|c|}
\hline & $\begin{array}{l}\mathrm{P} \\
(1)\end{array}$ & $\begin{array}{l}\text { PR } \\
\text { (2) }\end{array}$ & $\begin{array}{l}\text { Both } \\
\text { (3) }\end{array}$ & $\begin{array}{c}\text { Punishment } \\
\text { Decision } \\
\text { (4) }\end{array}$ & $\begin{array}{c}\text { Punishment } \\
\text { Level } \\
\text { (5) }\end{array}$ \\
\hline Transfer & $\begin{array}{c}-0.10 * * * \\
(0.01)\end{array}$ & $\begin{array}{c}-0.05 * * * \\
(0.01)\end{array}$ & $\begin{array}{c}-0.10 * * * \\
(0.01)\end{array}$ & $\begin{array}{c}-0.05 * * * \\
(0.00)\end{array}$ & $\begin{array}{c}-0.28 * * * \\
(0.03)\end{array}$ \\
\hline PR & & & $\begin{array}{c}-3.64 * * * \\
(0.95)\end{array}$ & $\begin{array}{c}-1.39 * * \\
(0.54)\end{array}$ & $\begin{array}{l}-2.26 \\
(2.70)\end{array}$ \\
\hline $\mathrm{PR} *$ Transfer & & & $\begin{array}{c}0.05 * * * \\
(0.01)\end{array}$ & $\begin{array}{c}0.00 \\
(0.01)\end{array}$ & $\begin{array}{c}0.05 \\
(0.05)\end{array}$ \\
\hline Wave & $\begin{array}{c}1.91 \\
(1.19)\end{array}$ & $\begin{array}{l}1.84 * \\
(1.07)\end{array}$ & $\begin{array}{c}1.88 * * \\
(0.80)\end{array}$ & $\begin{array}{c}1.26 * * \\
(0.51)\end{array}$ & $\begin{array}{c}2.19 \\
(2.45)\end{array}$ \\
\hline Constant & $\begin{array}{c}7.19 * * * \\
(0.91)\end{array}$ & $\begin{array}{c}3.57 * * * \\
(0.84)\end{array}$ & $\begin{array}{c}7.20 * * * \\
(0.79)\end{array}$ & $\begin{array}{l}-3.85 \\
(0.46)\end{array}$ & $\begin{array}{c}17.00 * * * \\
(2.22)\end{array}$ \\
\hline Observations & 539 & 539 & 1078 & 1078 & 191 \\
\hline No of subjects & 49 & 49 & 98 & 98 & 46 \\
\hline
\end{tabular}


Table 3 - The Demand for Costly Reward

\begin{tabular}{|c|c|c|c|c|c|}
\hline & $\begin{array}{l}\mathrm{P} \\
(1)\end{array}$ & $\begin{array}{l}\text { PR } \\
(2)\end{array}$ & $\begin{array}{l}\text { Both } \\
\text { (3) }\end{array}$ & $\begin{array}{c}\text { Reward } \\
\text { Decision } \\
\text { (4) }\end{array}$ & $\begin{array}{c}\text { Reward } \\
\text { Level } \\
\text { (5) }\end{array}$ \\
\hline Transfer & $\begin{array}{c}0.11 * * * \\
(0.01)\end{array}$ & $\begin{array}{c}0.08 * * * \\
(0.01)\end{array}$ & $\begin{array}{c}0.11 * * * \\
(0.01)\end{array}$ & $\begin{array}{c}0.05 * * * \\
(0.00)\end{array}$ & $\begin{array}{c}0.23 * * * \\
(0.02)\end{array}$ \\
\hline PR & & & $\begin{array}{c}0.58 \\
(1.52)\end{array}$ & $\begin{array}{c}-1.88 * * \\
(0.89)\end{array}$ & $\begin{array}{c}4.69 \\
(3.01)\end{array}$ \\
\hline $\mathrm{PR} *$ Transfer & & & $\begin{array}{c}-0.03 * * * \\
(0.01)\end{array}$ & $\begin{array}{l}-0.00 \\
(0.01)\end{array}$ & $\begin{array}{l}-0.04 \\
(0.03)\end{array}$ \\
\hline Wave & $\begin{array}{l}-0.08 \\
(1.82)\end{array}$ & $\begin{array}{c}1.06 \\
(2.16)\end{array}$ & $\begin{array}{c}0.51 \\
(1.41)\end{array}$ & $\begin{array}{c}0.85 \\
(0.75)\end{array}$ & $\begin{array}{l}-0.41 \\
(2.34)\end{array}$ \\
\hline Constant & $\begin{array}{l}-0.56 \\
(1.31)\end{array}$ & $\begin{array}{l}-0.52 \\
(1.57)\end{array}$ & $\begin{array}{l}-0.83 \\
(1.28)\end{array}$ & $\begin{array}{c}-4.03 * * * \\
(0.74)\end{array}$ & $\begin{array}{l}-5.80 \\
(2.13)\end{array}$ \\
\hline Observations & 506 & 539 & 1045 & 1045 & 331 \\
\hline No of subjects & 46 & 49 & 95 & 95 & 51 \\
\hline
\end{tabular}

(1) - (3) are linear regressions and (5) are linear regressions and the dependent variable is the number of points Player $\mathrm{C}$ assigned to Player A; (4) is a probit regression and the dependent variable takes a value of 1 if Player C rewarded A for a transfer $t$ and 0 otherwise; in (5) the dependent variable is truncated at zero; all regressions include individual random effects; observations from three individuals are dropped in regression (5) as they were outliers, however, adding them in the analysis does not affect qualitatively our results; * significant at $10 \%$ level; ** significant at 5\% level; *** significant at $1 \%$ level. 


\section{Appendix}

Table A1

\begin{tabular}{|c|c|c|c|c|c|c|}
\hline \multirow[t]{2}{*}{ Treatment } & \multicolumn{3}{|c|}{ Punishment } & \multicolumn{3}{|c|}{ Reward } \\
\hline & $\mathbf{P}$ & PR & Both & $\mathbf{R}$ & PR & Both \\
\hline 0 -transfer & $\begin{array}{c}10.45^{* * *} \\
(1.04)\end{array}$ & $\begin{array}{c}5.63 * * * \\
(1.11)\end{array}$ & $\begin{array}{c}10.45^{* * *} \\
(1.08)\end{array}$ & & & \\
\hline 10-transfer & $\begin{array}{c}7.92 * * * \\
(1.04)\end{array}$ & $\begin{array}{c}4.43 * * * \\
(1.11)\end{array}$ & $\begin{array}{c}7.92 * * * \\
(1.08)\end{array}$ & $\begin{array}{c}0.44 \\
(1.03)\end{array}$ & $\begin{array}{c}0.12 \\
(1.27)\end{array}$ & $\begin{array}{c}0.44 \\
(1.18)\end{array}$ \\
\hline 20-transfer & $\begin{array}{c}5.86 * * * \\
(1.04)\end{array}$ & $\begin{array}{c}3.37 * * * \\
(1.11)\end{array}$ & $\begin{array}{c}5.86 * * * \\
(1.08)\end{array}$ & $\begin{array}{c}1.07 \\
(1.03)\end{array}$ & $\begin{array}{c}0.02 \\
(1.27)\end{array}$ & $\begin{array}{c}1.07 \\
(1.18)\end{array}$ \\
\hline 30-transfer & $\begin{array}{c}3.84 * * * \\
(1.04)\end{array}$ & $\begin{array}{l}1.94 * \\
(1.11)\end{array}$ & $\begin{array}{c}3.84 * * * \\
(1.08)\end{array}$ & $\begin{array}{l}1.74 * \\
(1.03)\end{array}$ & $\begin{array}{c}0.94 \\
(1.27)\end{array}$ & $\begin{array}{l}1.74 * * \\
(1.18)\end{array}$ \\
\hline 40-transfer & $\begin{array}{c}2.53 * * \\
(1.04)\end{array}$ & $\begin{array}{c}2.29 * * \\
(1.11)\end{array}$ & $\begin{array}{l}2.53 * * \\
(1.08)\end{array}$ & $\begin{array}{c}2.39 * * \\
(1.03)\end{array}$ & $\begin{array}{c}0.59 \\
(1.27)\end{array}$ & $\begin{array}{c}2.39 * * \\
(1.18)\end{array}$ \\
\hline 50-transfer & $\begin{array}{c}1.43 \\
(1.04)\end{array}$ & $\begin{array}{c}0.45 \\
(1.11)\end{array}$ & $\begin{array}{c}1.43 \\
(1.08)\end{array}$ & $\begin{array}{c}4.17 * * * \\
(1.03)\end{array}$ & $\begin{array}{c}1.88 \\
(1.27)\end{array}$ & $\begin{array}{c}4.17 * * * \\
(1.18)\end{array}$ \\
\hline 60-transfer & $\begin{array}{c}0.67 \\
(1.04)\end{array}$ & $\begin{array}{c}0.33 \\
(1.11)\end{array}$ & $\begin{array}{c}0.67 \\
(1.08)\end{array}$ & $\begin{array}{c}5.11 * * * \\
(1.03)\end{array}$ & $\begin{array}{l}2.29 * \\
(1.27)\end{array}$ & $\begin{array}{c}5.11 * * * \\
(1.18)\end{array}$ \\
\hline 70-transfer & $\begin{array}{c}0.49 \\
(1.04)\end{array}$ & $\begin{array}{l}1.14 \\
(1.11)\end{array}$ & $\begin{array}{c}0.49 \\
(1.08)\end{array}$ & $\begin{array}{c}7.02 * * * \\
(1.03)\end{array}$ & $\begin{array}{l}3.31 * * \\
(1.27)\end{array}$ & $\begin{array}{c}7.02 * * * \\
(1.18)\end{array}$ \\
\hline 80-transfer & $\begin{array}{c}0.23 \\
(1.04)\end{array}$ & $\begin{array}{c}0.20 \\
(1.11)\end{array}$ & $\begin{array}{c}0.23 \\
(1.08)\end{array}$ & $\begin{array}{c}7.96 * * * \\
(1.03)\end{array}$ & $\begin{array}{c}5.35 * * * \\
(1.27)\end{array}$ & $\begin{array}{c}7.96 * * * \\
(1.18)\end{array}$ \\
\hline 90-transfer & $\begin{array}{l}-0.11 \\
(1.04)\end{array}$ & $\begin{array}{c}0.00 \\
(1.11)\end{array}$ & $\begin{array}{l}-0.11 \\
(1.08)\end{array}$ & $\begin{array}{c}9.02 * * * \\
(1.03)\end{array}$ & $\begin{array}{c}6.57 * * * \\
(1.27)\end{array}$ & $\begin{array}{c}9.02 * * * \\
(1.18)\end{array}$ \\
\hline 100-transfer & & & & $\begin{array}{c}10.70 * * * \\
(1.03)\end{array}$ & $\begin{array}{c}7.14 * * * \\
(1.27)\end{array}$ & $\begin{array}{c}10.70 * * * \\
(1.18)\end{array}$ \\
\hline PR & & & $\begin{array}{l}-0.10 \\
(1.31)\end{array}$ & & & $\begin{array}{c}0.81 \\
(1.79)\end{array}$ \\
\hline PR*0-transfer & & & $\begin{array}{c}-4.82 * * * \\
(1.31)\end{array}$ & & & \\
\hline PR*10-transfer & & & $\begin{array}{c}-3.49 * * \\
(1.31)\end{array}$ & & & $\begin{array}{l}-0.31 \\
(1.65)\end{array}$ \\
\hline PR*20-transfer & & & $\begin{array}{c}-2.59 * * \\
(1.31)\end{array}$ & & & $\begin{array}{l}-1.05 \\
(1.65)\end{array}$ \\
\hline PR*30-transfer & & & $\begin{array}{l}-1.90 \\
(1.31)\end{array}$ & & & $\begin{array}{l}-0.80 \\
(1.65)\end{array}$ \\
\hline PR*40-transfer & & & $\begin{array}{l}-0.25 \\
(1.31)\end{array}$ & & & $\begin{array}{l}-1.80 \\
(1.65)\end{array}$ \\
\hline $\mathrm{PR} * 50$-transfer & & & $\begin{array}{l}-0.98 \\
(1.31)\end{array}$ & & & $\begin{array}{l}-2.30 \\
(1.65)\end{array}$ \\
\hline $\mathrm{PR}^{*} 60$-transfer & & & $\begin{array}{l}-0.35 \\
(1.31)\end{array}$ & & & $\begin{array}{l}-2.82^{*} \\
(1.65)\end{array}$ \\
\hline PR*70-transfer & & & $\begin{array}{c}0.65 \\
(1.31)\end{array}$ & & & $\begin{array}{c}-3.72 * * \\
(1.65)\end{array}$ \\
\hline PR*80-transfer & & & $\begin{array}{l}-0.02 \\
(1.31)\end{array}$ & & & $\begin{array}{l}-2.61^{\dagger} \\
(1.65)\end{array}$ \\
\hline PR*90-transfer & & & $\begin{array}{c}0.10 \\
(1.31)\end{array}$ & & & $\begin{array}{l}-2.45^{\dagger} \\
(1.65)\end{array}$ \\
\hline PR*100-transfer & & & & & & $\begin{array}{c}-3.55^{* *} \\
(1.65)\end{array}$ \\
\hline Constant & $\begin{array}{c}0.10 \\
(0.93)\end{array}$ & $\begin{array}{c}0.00 \\
(0.93)\end{array}$ & $\begin{array}{c}0.10 \\
(0.93)\end{array}$ & $\begin{array}{c}0.44 \\
(1.14)\end{array}$ & $\begin{array}{c}1.25 \\
(1.37)\end{array}$ & $\begin{array}{c}0.44 \\
(1.29)\end{array}$ \\
\hline Observations & 539 & 539 & 1078 & 506 & 539 & 1045 \\
\hline Individuals & 49 & 49 & 98 & 46 & 49 & 95 \\
\hline
\end{tabular}


Figure A1 - The Demand for Costly Punishment by Individual

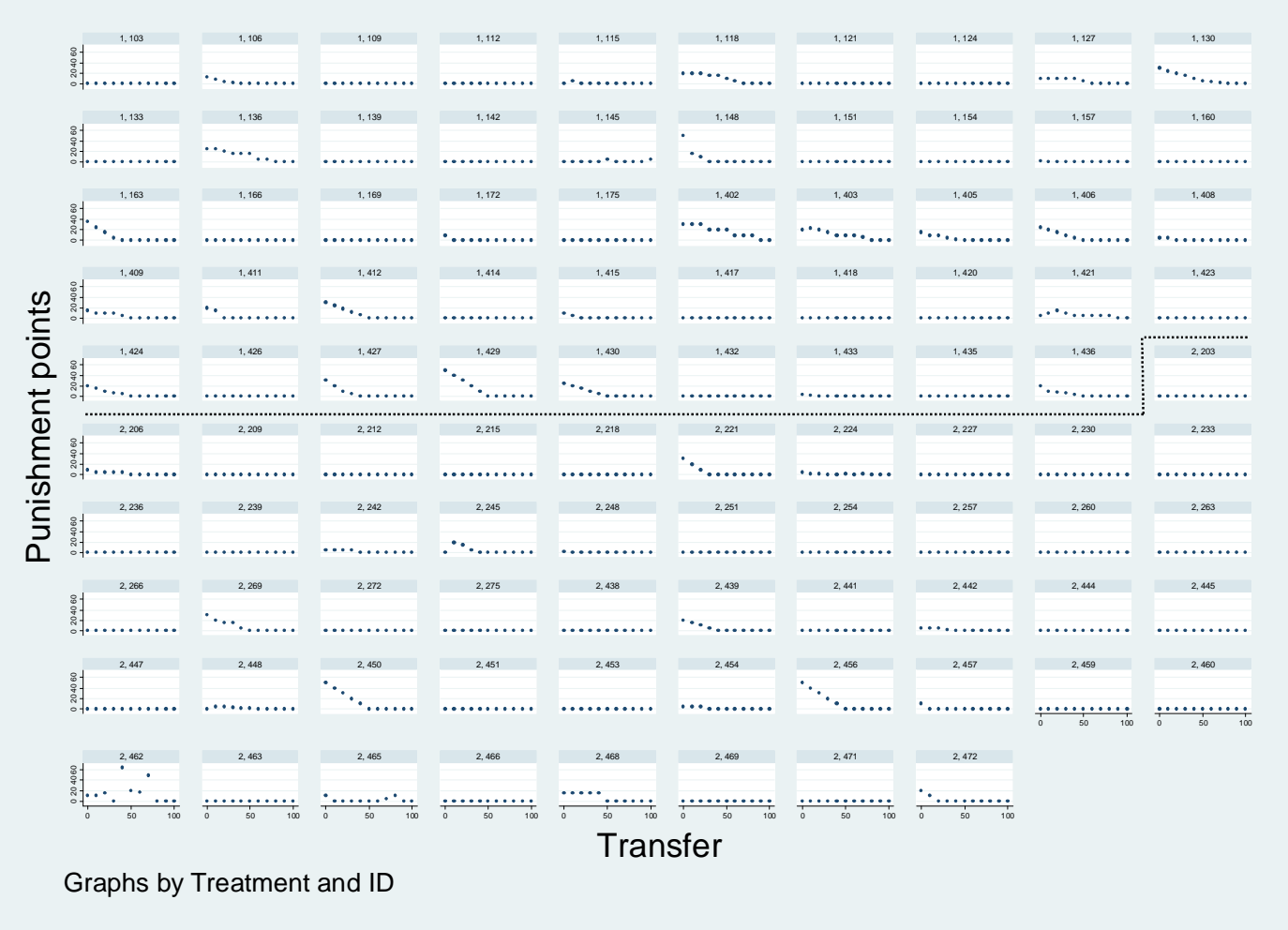

Figure A2 - The Demand for Costly Reward by Individual

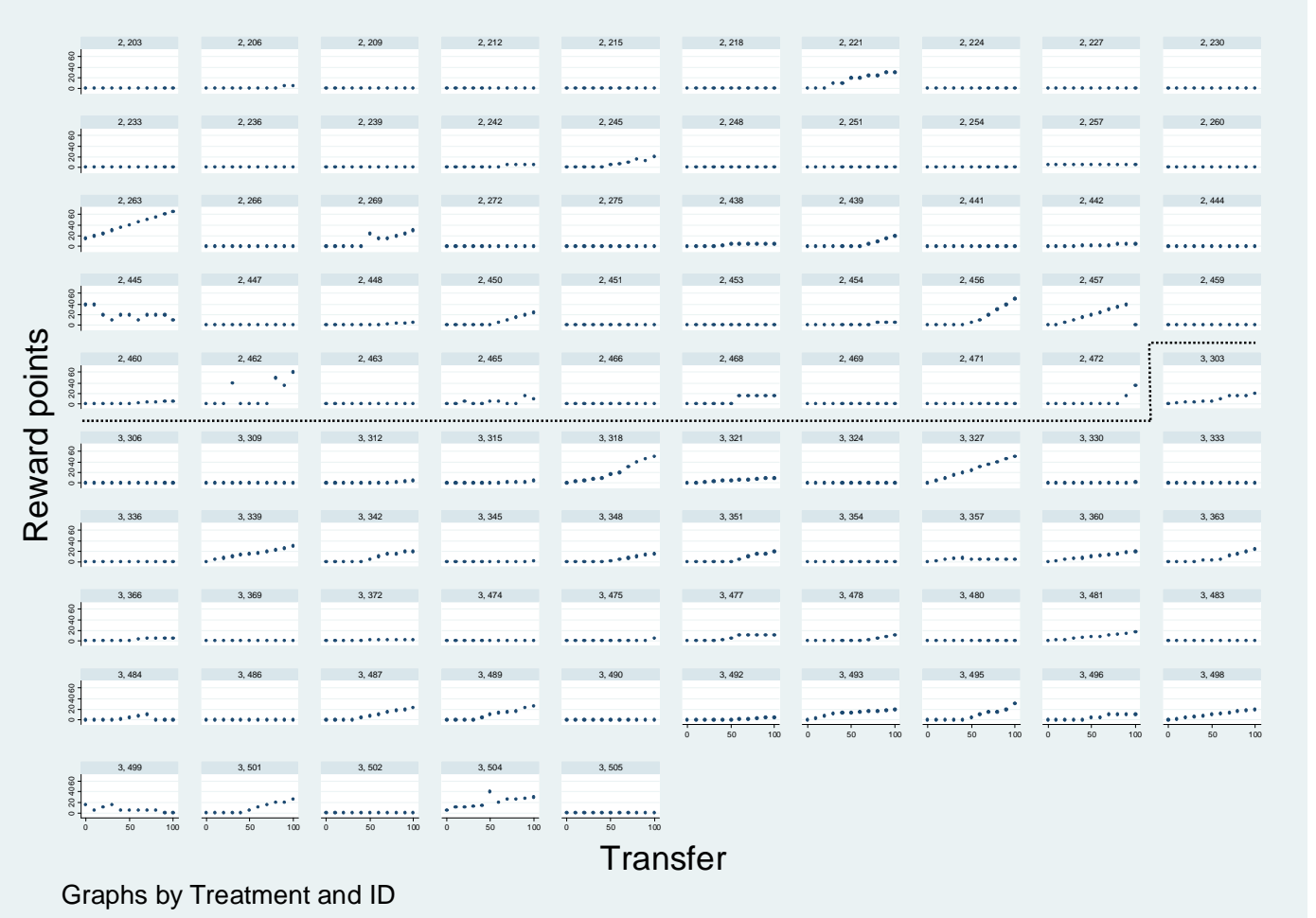

The first digit in each subfigure indicates the treatment in which the individual participated $(1=$ Treatment P; $2=$ Treatment PR; $3=$ Treatment $\mathrm{R})$. The number after the comma is a unique subject ID. The dashed lines help separate visually subjects belonging to a different treatment. 